\title{
The Association of Environmental Changes and the Replacement of Mosquito Fauna in the Colombo District, Sri Lanka
}

\author{
B.A.S. Priyangika ${ }^{1}$, B.G.D.N.K. De Silva ${ }^{1}$, D.P.W. Jayatunga-Katuwawalage ${ }^{1}$ \\ and M.B. Wickramasinghe ${ }^{2}$ \\ ${ }^{1}$ Department of Zoology, University of Sri Jayewardenepura, Nugegoda, Sri Lanka. \\ ${ }^{2}$ Retired Entomologist, Anti-Malaria Campaign, Colombo 5, Sri Lanka.
}

Date Received: 18-01-2013 Date Accepted: 08-04-2014

\begin{abstract}
A mosquito survey was carried out for 8 months between October 2009 and May 2010 in 12 randomly selected urban (6) and semi-urban (6) areas in the Colombo District of Sri Lanka. Thirty eight mosquito species were identified from which Anopheles interruptus, An. pseudojamesii, Aedes stevensoni, Ae. edwardsi, Ae. vittatus, Culex barraudi, Cx. fatigans, $C x$. univittatus, $C x$. aculeatus, Cx. purplexus, $C x$. spiculosus, $C x$. quadripalpis, $C x$. halifaxi, Uranotaenia atra, Ur. unguiculata were new findings that were not recorded during a previous survey conducted in 1981-1982 in the same locations. Rainfall had a direct relationship $(p=0.000)$ with the distribution and the density of mosquitoes. Unplanned urbanization, anthropogenic activities and irregular or non-disposal of domestic waste products may have led to population replacement of the mosquito fauna in these locations.
\end{abstract}

Keywords: environmental changes, mosquito fauna, Sri Lanka

\section{Introduction}

Mosquitoes are insects of the Order Diptera and Family Culicidae (Service, 2004). There are about 4,000 known mosquito species distributed worldwide (WHO, 2007). However, less than $10 \%$ are regarded as efficient vectors of diseases which directly or indirectly cause a severe impact on human health and welfare. Anopheles culicifacies is the major vector of malaria in Sri Lanka while An. subpictus, under favourable ecological conditions acts as a secondary vector. Several other Anophelines including An. annularis, An. barbirostris, An. jamesii, An. nigerrimus, An. peditaeniatus, An. tessellatus and An. varuna occur in the island and several of them can be regarded as potential vectors of malaria (Perera et al., 2008). Both Aedes aegypti and Ae. albopictus are vectors of dengue, dengue haemorrhagic fever and chickungunya. Culex tritaeniorhynchus, Cx. gelidus transmit the Japanese encephalitis virus. Urban filariasis is transmitted by $C x$. quinquefasciatus while rural filariasis is transmitted by Mansonia annulifera, Ma. indiana and Ma. uniformis (Service, 2004). Armigeres subalbatus is a vector of dirofilaria for domestic cats and dogs. Chelliah et al. (1986) and Chelliah \& Jayasekara (1981) listed 131 species of mosquitoes belonging to 16 genera recorded from Sri Lanka. Chelliah et al. (1986) subsequently reported 45 species in surveys carried out in the Colombo District during the period 1981-1982. During the period of 1982-2009 there has been a shift in the environmental conditions in the

\footnotetext{
*Correspondence: nissankakolitha@gmail.com Tel: +94112802914

ISSN 2235-9370 Print/ISSN 2235-9362 Online (C University of Sri Jayewardenepura
} 
Colombo District. Internal migrations due to rapid development of industries, education and increased school attendance, garment factories, occupational distribution, decrease of agricultural lands, increase of slum areas, urbanization and establishment of head offices of ministries and widening of the parliament complex and office quarters in Colombo had caused severe impacts on the environment. All such changes may have indirectly resulted in climatic change leading to a changing of breeding habitats of mosquitoes. Amerasinghe et al. in 1994 conducted a study in the area of the Mahaweli project in order to check and compare breeding patterns of ground water mosquitoes before and after irrigation according to the changing of breeding habitats. The present study focused on assessing changes in the mosquito fauna in the localities previously surveyed in the Colombo District, Sri Lanka by Chelliah et al. (1986).

\section{Materials and Methods}

\subsection{The study area}

Investigations were carried out in 12 randomly selected semi-urbanized areas namely, Beddagana, Battaramulla, Madiwela, Pelawatte, Thalapathpitiya, Thalawathugoda, and urbanized areas namely, Ethulkotte, Kotte, Nawala, Nugegoda, Pitakotte, Welikada in the Colombo District of Sri Lanka.



Fig. 1: Townships and villages of the study area in the Colombo District. Star denotes the Parliamentary Complex

\begin{tabular}{|c|c|c|c|}
\hline tr & Parliament Complex & 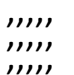 & Marshy land \\
\hline ….... & Diyawanna Oya & $\begin{array}{l}+++ \\
++ \\
+++\end{array}$ & Paddy field \\
\hline
\end{tabular}

\subsection{Mosquito surveys}

Mosquito surveys were carried out fortnightly during the period October 2009 to May 2010. Both adult and larval collections were made. A total of 30 houses and the surroundings were investigated between 05.00-21.00 hours. Adults were gathered by cattle-baited net-trap 
and exit/inlet window trap collections. Resting mosquitoes were also collected from vegetation with Hand Nets and from domestic animals using aspirators. Larval collections were made using earthenware Pot-traps and Ovitraps. Larvae from streams were collected by dipping with a standard Ladle and larvae breeding in artificial containers were gathered using a dropper. Representative sample of adults, third and fourth stage larvae were identified using morphotaxonomic keys of Amerasinghe et al. (1992) and Col \& Sewel $(1933,1934)$. The first and second stage larvae were reared in the laboratory to third and fourth stages and pupae to adults respectively which were then identified morphologically.

\section{Results}

Thirty eight species of mosquitoes belonging to seven genera and 11 sub-genera were collected during the study period, of which 18 species are medically important (Tables 1 and 2). Twenty-three species of mosquitoes were commonly recorded both in the previous and the present surveys in the same localities (Table 1). Mosquito species totaling 15 in the present study were not recorded in the previous survey while 21 species collected in the previous survey were not found in the present survey (Table 2). Culex quinquefasciatus was the predominant species, constituting $22.58 \%$ (Table 3) and was particularly dense in the urbanised areas in the Colombo District. During the study period the ambient temperature and humidity ranged from $27.59^{\circ} \mathrm{C}-29.04^{\circ} \mathrm{C}$ and $66 \%-86 \%$, respectively (Fig. 2). $P$-values obtained using MINITAB 14 for mosquito percentage in relation to rainfall, humidity and temperature amounted to $p=0.000,0.076$ and 0.678 respectively.

Table 1: Mosquito species commonly found in previous (1981-1982) and present (2009-2010) surveys in Colombo District.

\begin{tabular}{|c|c|c|}
\hline $\begin{array}{l}\text { 1. Anopheles(Ano) } \\
\text { barbirostris* }\end{array}$ & 9. Ae. (Stg) albopictus* & 17. $C x .($ Cux $)$ sitiens* \\
\hline 2..An. (Ano) nigerrimus* & 10. Armigeres (Arm)subalbatus* & 18. $C x .($ Cux)tritaeniorhynchus* \\
\hline 3. An. (Ano) peditaeniatus & 11. Culex (Cux) fuscocephala* & 19. Cx. $($ Cux $)$ whitmorei \\
\hline 4. An. (Cel) jamesii* & 12. Cx. (Eum) brevipalpis & 20. Ficalbia minima \\
\hline 5. An. (Cel) maculatus* & 13. Cx. (Lop) infantulus & 21. Mansonia (Mnd)annulifera* \\
\hline 6. An. (Cel) pallidus & 14. $C x$. (Lop) minutissimus & 22. Ma. (Mnd) indiana* \\
\hline 7. An. (Cel) subpictus* & 15. Cx. $(C u x)$ gelidus* & 23. Ma. $($ Mnd $)$ uniformis* \\
\hline 8. Aedes (Stg) aegypti* & 16. $C x .(C u x)$ quinquefasciatus* & \\
\hline
\end{tabular}

* Medically important species

Table 2: Replacement of mosquito species found in the Colombo District during 1981-1982 survey and 2009-2010 (present) survey.

\begin{tabular}{ll}
\hline $\begin{array}{l}\text { Mosquito species exclusively } \\
\text { recorded in 1981-1982 survey }\end{array}$ & $\begin{array}{l}\text { Mosquito species recorded exclusively } \\
\text { in 2009-2010 survey }\end{array}$ \\
\hline 1. Anopheles (Cel) tessellatus & 1. An. (Ano) interruptus \\
2. An. (Cel) vagus & 2. An. (Cel) pseudojamesii \\
3. Aedes (Fin) gubernatoris & 3. Ae. (Fin) stevensoni \\
4. Ae. (Adm) pipersalatus & 4. Ae. (Stg) edwardsi* \\
5. Ae. (Adm) vexans & 5. Ae. (Stg) vittatus \\
6. Ae. (Neo) lineatopennis & 6. Cx. (Lut) halifaxi \\
7. Ae. (Ver) pseudomediofasciatus & 7. Cx. (Lop)aculeatus
\end{tabular}



8. Coquillettidia (Coq) crassipes
8. Cx. (Lop) spiculosus
9. Culex (Lut) fuscanus
10. Cx. (Cui) nigropunctatus
9. $C x$. (Lop) quadripalpis
11. Cx. (Cui) pallidothorax
10. Cx. (Cux) barraudi
12. $C x$. (Cui) spathifurca
11. $C x$. (Cux) fatigans
12. $C x .($ Cux $)$ purplexus
13. $C x .(C u x)$ infula
14. Cx. (Cux) pseudovishnui
13. $C x$. (Cux) univittatus*
14. Ur. (Ura) atra
15. $C x$. (Cux) sinensis
16. Mimomyia (Mim) hybrida
15. Ur. (Ura) unguiculata
17. Mi. (Eto) luzonensis
18. Malaya genurostris
19. Toxorhynchites (Tox) splendens
20. Uranotaenia (Ura) lateralis
21. Ur. $\left(P f_{c}\right)$ bicolor

(Adm) - Sub Genus Aedimorphus
(Arm) - Sub Genus Armigeres
(Coq) - Sub Genus Coquillettidia
(Cux) - Sub Genus Culex
(Eum) - Sub Genus Eumelanomyia
(Lop) - Sub Genus Lophoceratomyia
(Mim) - Sub Genus Mimomyia
(Neo) - Sub Genus Neomelaniconio
(Stg) - Sub Genus Stegomyia
(Ura) - Sub Genus Uranotaenia
(Ano) - Sub Genus Anopheles
(Cel) - Sub Genus Cellia
(Cui) - Sub Genus Culiciomyia
(Eto) - Sub Genus Etorleptiomyia
(Fin) - Sub Genus Finlaya
(Lut) - Sub genus Lutzia
(Mnd) - Sub Genus Mansonioides
$(P f c)$ - Sub Genus Pseudoficalbia
(Tox) - Sub Genus Toxorhynchites
(Ver) - Sub Genus Verrallina

Table 3: Total numbers and percentages of adults and larvae of each mosquito species collected from the Colombo District in the present survey (2009-2010).

\begin{tabular}{|c|c|c|c|c|c|}
\hline Species & $\begin{array}{r}\text { Total adults } \\
\text { \& larvae }\end{array}$ & $(\%)$ & Species & $\begin{array}{r}\text { Total adults } \\
\& \text { larvae }\end{array}$ & $(\%)$ \\
\hline 1. An. (Ano) barbirostris & 8 & 0.02 & 20. Cx. (Lop) aculeatus & 2 & 0.006 \\
\hline 2. An. (Ano) nigerrimus & 783 & 2.57 & 21. Cx. (Lop) spiculosus & 1 & 0.003 \\
\hline 3. An. (Ano)peditaeniatus & 11 & 0.03 & 22. Cx. (Lop) quadripalpis & 1 & 0.003 \\
\hline 4. An.(Ano) interruptus & 859 & 2.82 & 23. Cx. (Cux) fuscocephala & 1 & 0.003 \\
\hline 5. An.(Cel) jamesii & 10 & 0.03 & 24. Cx. (Cux) gelidus & 4,851 & 15.94 \\
\hline 6. An.(Cel) maculatus & 60 & 0.19 & 25. Cx. (Cux)quinquefasciatus & 6,780 & 22.58 \\
\hline 7. An. $(\mathrm{Cel})$ pallidus & 112 & 0.36 & 26. Cx. (Cux) sitiens & 2 & 0.006 \\
\hline 8. An.(Cel) subpictus & 4 & 0.01 & 27. Cx.(Cux)tritaeniorhynchus & 4,335 & 14.25 \\
\hline 9. An.(Cel)pseudojamesii & 90 & 0.29 & 28. $C x .(C u x)$ whitmorei & 21 & 0.06 \\
\hline 10. Ae.(Fin) stevensoni & 2 & 0.006 & 29. Cx. (Cux) barraudi & 17 & 0.05 \\
\hline 11. Ae.(Stg) aegypti & 508 & 1.67 & 30. $C x .($ Cux $)$ fatigans & 4 & 0.01 \\
\hline 12. Ae.(Stg) albopictus & 5,740 & 18.87 & 31. Cx. (Cux) purplexus & 2 & 0.006 \\
\hline 13. Ae.(Stg) edwardsi & 7 & 0.02 & 32. $C x .($ Cux $)$ univittatus & 23 & 0.07 \\
\hline 14. Ae.(Stg) vittatus & 15 & 0.04 & 33. Fi. minima & 5 & 0.01 \\
\hline 15. Ar.(Arm) subalbatus & 3,781 & 12.43 & 34. Ma. (Mnd) annulifera & 299 & 0.98 \\
\hline 16. Cx. (Lut) halifaxi & 7 & 0.02 & 35. Ma. $($ Mnd) indiana & 415 & 1.36 \\
\hline 17. Cx.(Eum) brevipalpis & 1 & 0.003 & 36. Ma. (Mnd) uniformis & 1,510 & 4.96 \\
\hline 18. Cx.(Lop )infantulus & 23 & 0.07 & 37. Ur. atra & 8 & 0.02 \\
\hline \multirow[t]{2}{*}{ 19. Cx.(Lop)minutissimus } & 27 & 0.08 & 38. Ur. unguiculata & 3 & 0.009 \\
\hline & & & Total & 30,418 & 100 \\
\hline
\end{tabular}


Table 4: Larval habitats of mosquito species collected in the present survey (2009-2010).

\begin{tabular}{|c|c|c|c|c|c|c|c|c|c|c|c|c|}
\hline \multirow[b]{2}{*}{ Larval species } & \multirow[b]{2}{*}{ 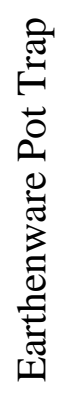 } & & \multicolumn{10}{|c|}{ Larval/pupal habitats } \\
\hline & & : & 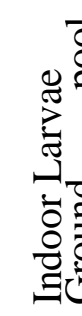 & 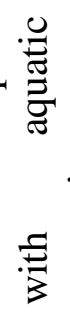 & 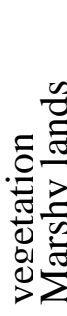 & $\begin{array}{l}\frac{\infty}{0} \\
\frac{2}{0} \\
\frac{2}{\sigma}\end{array}$ & 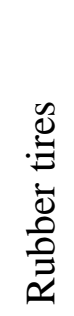 & 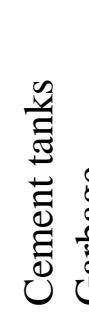 & 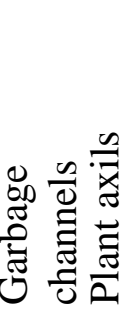 & &  & $\stackrel{0}{3}$ \\
\hline Anopheles interruptus & & & & $\mathrm{x}$ & & $\mathrm{x}$ & & & & & & \\
\hline An. nigerrimus & & & & $\mathrm{x}$ & & $\mathrm{x}$ & & & & & & \\
\hline Aedes aegypti & $\mathrm{x}$ & $\mathrm{x}$ & $\mathrm{X}$ & & & & $\mathrm{x}$ & $\mathrm{X}$ & & $\mathrm{X}$ & & \\
\hline Ae. albopictus & $\mathrm{x}$ & $\mathrm{x}$ & $\mathrm{x}$ & $x$ & & & $\mathrm{x}$ & $\mathrm{X}$ & $\mathrm{x}$ & $\mathrm{X}$ & & \\
\hline Ae. edwardsi & & & & & & & & & & $\mathrm{X}$ & & \\
\hline Ae. stevensoni & & & & & & & & & & $\mathrm{X}$ & & \\
\hline Ae. vittatus & & $\mathrm{x}$ & & & & & $\mathrm{X}$ & & & $\mathrm{X}$ & & \\
\hline Armigeres subalbatus & & & & & & & & & $\mathrm{x}$ & $\mathrm{x}$ & & \\
\hline Culex aculeatus & $\mathrm{x}$ & & & & & & & & & & & \\
\hline Cx. barraudi & $\mathrm{x}$ & & & & & & & & & & & \\
\hline Cx. brevipalpis & $\mathrm{x}$ & & & & & & & & & $\mathrm{x}$ & & \\
\hline$C x$. fatigans & & & & & & & & & $\mathrm{x}$ & & & \\
\hline Cx. fuscocephala & $\mathrm{x}$ & & & & & & & & & & & \\
\hline Cx. gelidus & $\mathrm{x}$ & $\mathrm{x}$ & & $\mathrm{x}$ & & $\mathrm{x}$ & & & $\mathrm{x}$ & & & $x$ \\
\hline Cx. halifaxi & & & & & & $\mathrm{x}$ & & & & & & \\
\hline$C x$. infantulus & $\mathrm{x}$ & & & & & $\mathrm{x}$ & & & & & & $\mathrm{x}$ \\
\hline Cx. minutissimus & $\mathrm{x}$ & & & & & $\mathrm{x}$ & & & & & & $\mathrm{X}$ \\
\hline Cx. quinquefasciatus & & & & & & $\mathrm{X}$ & & & $\mathrm{x}$ & $\mathrm{X}$ & & \\
\hline Cx. sitiens & $\mathrm{x}$ & & & & & & & & & $\mathrm{x}$ & & \\
\hline CX. spiculosus & $\mathrm{x}$ & & & & $x$ & & & & & & & $\mathrm{x}$ \\
\hline Cx. tritaeniorhynchus & $\mathrm{x}$ & $\mathrm{x}$ & & $\mathrm{x}$ & & $\mathrm{x}$ & & & & & & \\
\hline$C x$. univittatus & $\mathrm{x}$ & & & & & & & & $\mathrm{x}$ & & & \\
\hline Cx. whitmorei & $\mathrm{x}$ & & & & & & & & & & $\mathrm{x}$ & \\
\hline Ficalbia minima & & & & & & & & & & & $\mathrm{x}$ & \\
\hline Mansonia annulifera & & & & & & & & & & & $\mathrm{x}$ & \\
\hline Ma. indiana & & & & & & & & & & & $\mathrm{x}$ & \\
\hline Ma. uniformis & & & & & & & & & & & $\mathrm{x}$ & \\
\hline Uranotaenia atra & & & & & $x$ & & & & & & & \\
\hline Ur. unguiculata & & & & & $\mathrm{x}$ & & & & & & & \\
\hline
\end{tabular}




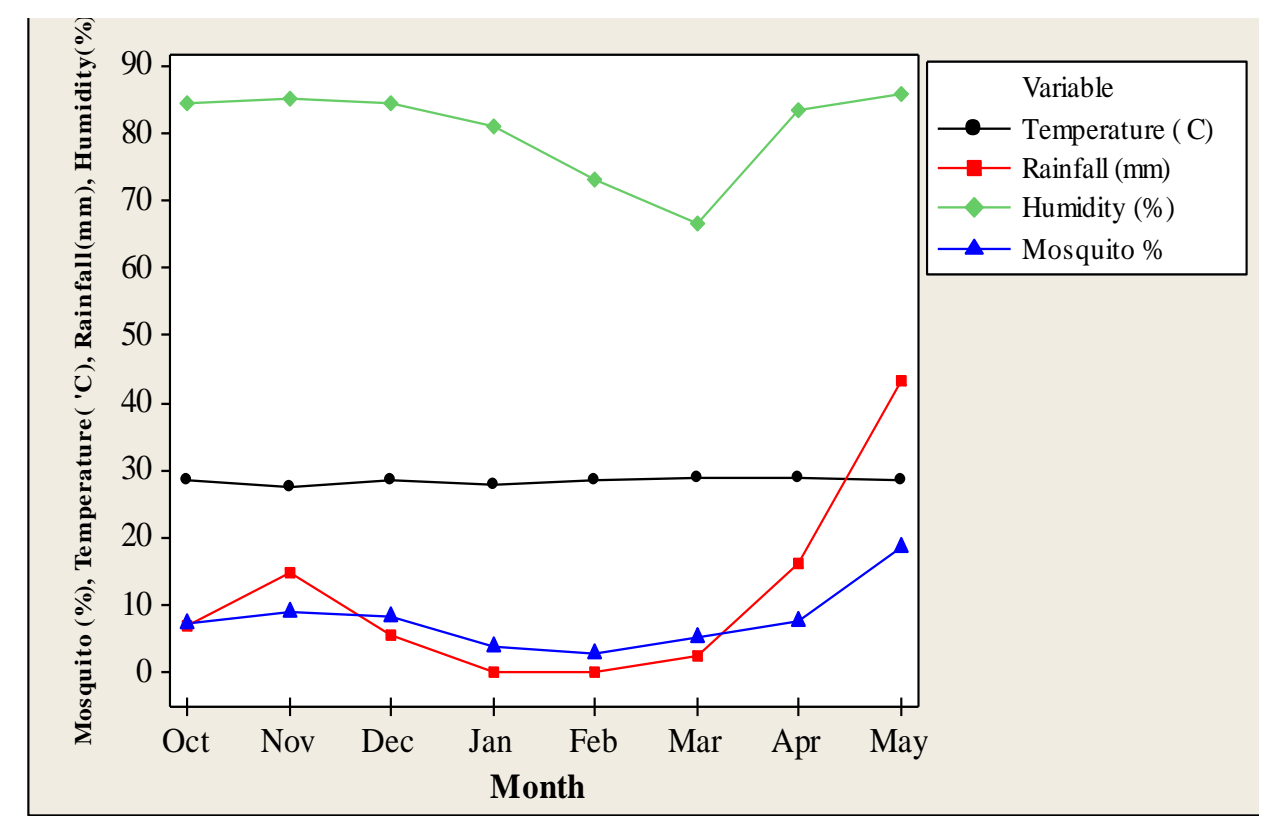

Fig. 2: The impact of Temperature, Rainfall and Humidity on the percentage of mosquitoes collected monthly during the current study period 2009-2010.

\section{Discussion}

The present mosquito survey was carried out in the same areas previously surveyed by Chelliah et al. (1986), during which a total of 44 species representing nine genera were detected. In the previous survey (1981-1982), some of these areas were considered rural, some semi-urban while some were identified as urban. The categories of urbanized, semiurbanized and rural areas used in the current study were based on the official classification specified by the respective Municipal or the Urban Council. During the present study, all the study areas were found to be semi-urban or urban to a greater or lesser extent according to the official classification. The present study covered a total of 30 houses in the same areas while the previous study had investigated a total of 15 houses at each visit. The highest percentage of mosquito species amounting to $22.58 \%$ was formed by Culex quinquefasciatus breeding in polluted waters. Such suitable habitats for profuse breeding of this mosquito species have been created due to disposal of toilet and kitchen waters by the residents of areas in to branches of the "Diyawanna oya", that flow through these areas. Cx. gelidus and $C x$. tritaeniorhynchus, which breed more or less under similar conditions formed $15.94 \%$ and $14.25 \%$ respectively $C x$. quinquefasciatus, $C x$. tritaeniorhynchus and $C x$. gelidus were found in higher number in urban areas than in semi-urban areas as the water was polluted due to stagnant water bodies in blocked drains and uncovered dilapidated toilet pits. Ar. subalbatus being a zoophilic, outdoor mosquito was detected in garbage channels and artificial containers in domestic environments as its main targets are domestic animals such as cats and dogs.

Outdoor mosquitoes, Aedes aegypti and Ae. albopictus, formed $1.67 \%$ and $18.87 \%$ respectively. Human activities in these areas had created artificial container habitats suitable for breeding of these two species despite massive campaigns of source reduction been conducted by Municipal councils and other government institutions. 
A total of 2,250 of medically important adult female mosquitoes were collected from human dwellings within 12 months in 1981-1982 period which had drastically reduced to a value of 1,603 during eight months study period of the current study, within the same area after 27 years.

Rainfall is a major climatic factor that creates habitats for mosquito breeding. The current study clearly indicated a significant relationship $(p=0.000)$ between mosquito density and rainfall. Mean monthly rainfall for 1981-1982 and 2009-2010 periods were $156.3 \mathrm{~mm}$ (Climatic Data, 1981-1982- Department of Meteorology, Sri Lanka) and 264.1mm (Climatic Data, 2009-2010: Department of Meteorology, Sri Lanka), respectively. Mean rainfall of the study area had much increased within the past 27 years. The respective $p$ values for humidity and temperature with mosquito density, $p=0.076$ and 0.678 respectively showed no relationship and hence they could not be considered as significant climatic factor changes accounting for mosquito density, within the study area during the study period. It is noteworthy that a study conducted in Saudi Arabia (Alshehri, 2013) has shown that there is a strong correlation between Ae. aegypti mosquito density and climatic factors of temperature and relative humidity.

Comparison of the mosquito population compositions of the two surveys clearly shows the changes taken place of mosquito species in the Colombo District within a span of 27 years. It seems to have been caused by changes in the environment leading to creation of suitable breeding habitats for some mosquito species. Human population in the Colombo District had increased to 788,759 from 1981 to 2009 due to internal migration (Sri Lanka, Ministry of Finance and Planning, Department of Census and Statistics, 2009). Even though the recent development projects spearheaded by the government (from 2009), ("Maga Neguma"- Road development, "Gama Neguma"- build houses and home gardens, "Diwi Neguma" - Agriculture etc.) have improved the quality of life to some extent, the results of the present study are indicative that unplanned urbanization, town development, destruction of vegetation, filling marshes, irregular or non-disposal of house-hold waste products such as artificial containers, polythene bags, yoghurt cups etc. are major contributory factors for breeding of vector mosquito species of serious human diseases. Breeding habitats formed due to these activities for non-vector mosquitoes too would form a health problem as their bites affect humans physically and mentally.

Similar studies conducted elsewhere (Rejmánková et al., 2010) have indicated that in marshes, the replacement of a certain mosquito by another can be due to changes in vegetations caused by increasing of nutrients from agricultural practices. The human induced changes in wetland habitats combined with habitat selection by mosquito females can lead to replacement of a less efficient disease vector by a more efficient one.

The present study confirms that the mosquito replacement detected in the study area after 27 years of time is due to environmental change caused by urbanization in the form of increased mosquito breeding habitats.

\section{Conclusion}

Thirty eight mosquito species were identified of which Anopheles interruptus, An. pseudojamesii, Aedes stevensoni, Ae edwardsi, Ae. vittatus, Culex barraudi, Cx. fatigans, Cx. univittatus, Cx. aculeatus, Cx. purplexus, Cx. spiculosus, Cx. quadripalpis, Cx. halifaxi, Uranotaenia atra and Ur. unguiculata were not recorded previously in the period 1981-1982 from the same locations. Twenty one species which were recorded in the previous study 
(1981-1982) were not recorded in this survey. This mosquito replacement may be a result of human activities which include unplanned urbanization together with creation of unattended stagnant water bodies and discarded receptacles which spontaneously become mosquito breeding habitats. There were 18 medically important vector mosquitoes recorded reiterating 16 previous records in the study area indicating that attention should be paid for stringent measures adopted to control vector mosquitoes in the Colombo District.

\section{Acknowledgements}

The authors wish to thank officers in the Sugarcane Research Institute, Medical Research Institute, Anti Filariasis Unit, Anti Malaria Campaign and Dengue Control Unit for the support given in acquiring data as well as in identifying mosquito species.

\section{References}

Alshehri, M.S.A., 2013. Dengue Fever outburst and its relationship with climatic factors. World Applied Sciences Journal, 22(4):506-515.

Amerasinghe, F.P., Amerasinghe, P.H., Karunaratne, S.H.P.P., Peiris, J.H.M., Ratnayake, C.B., Tsai T.F., 1992. Japanese encephalitis in Sri Lanka: the study of an epidemic: vector incrimination, porcine infection and human disease. Transactions of the Royal Society of Tropical Medicine and Hygiene, 86(3):307-313.

Amerasinghe, F.P., Indrajith, N.G., 1994. Post irrigation breeding patterns of ground water mosquitoes in an area of the Mahaweli Project, Sri Lanka. Journal of Medical Entomology, 31:516-523.

Chelliah, R.V., Jayasekara, N., 1981. An annotated checklist of mosquitoes of Sri Lanka, Department of Entomology, Medical Research Institute, Colombo 8, MAB-UNESCO Man and Biosphere National Committee for Sri Lanka, Publication no. 8. Published by the National Science Foundation, Colombo 07, Sri Lanka.

Chelliah, R.V., Jansen, C.G., Jayasekara, N., Pathmanathan, S., 1986. Mosquito studies in Sri Jayewardenepura-the New Capital of Sri Lanka. Mosquito Borne Diseases Bulletin, 2(4), 87-93.

Col, L., Sewel, R. B. S., 1933. The fauna of British India including Ceylon and Burma, Diptera, Vol. V, Family Culicidae, Tribes Anophelini. Today and Tomorrow's Printers \& Publishers, New Delhi-110005.

Col, L., Sewel, R. B. S., 1934. The fauna of British India including Ceylon and Burma, Diptera, Vol. V, Family Culicidae, Tribes Megarhinini and Culicini. Today and Tomorrow's Printers $\&$ Publishers, New Delhi-110005.

Ministry of Finance \& Planning, Department of Census and Statistics, 1981. Census of population and Housing, population by sex in rural areas and Towns of AGA Divisions Colombo, Sri Lanka. District Report, Vol. 1: Part 1.

Perera, M.D.B., Hemingway, J., Karunaratne, S.H.P.P., 2008. Multiple insecticide resistance mechanisms involving metabolic changes and insensitive target sites selected in Anopheline vectors of malaria in Sri Lanka. Malaria Journal, 7:168.

Rejmánková, E., 2010. Marshes, mosquitoes and malaria and what about nutrients. SWS Research Brief 0001.

Service, M.W., 2004. Medical entomology for students, $3^{\text {rd }}$ edition, the press syndicate of the University of Cambridge, Cambridge, United Kingdom, pp.1-73.

WHO, 2007. Anopheline species complexes in South and South-East Asia, World Health Organization, Regional Office for South-East Asia, SEARO Technical Publication No: 57. 